\title{
LA POLÍTICA CRIMINAL Y EL DAÑO SOCIAL EN COSTA RICA
}

\section{CRIMINAL POLITICS AND SOCIAL HARM IN COSTA RICA}

\author{
Irina Sibaja López
}

RESUMEN

El presente trabajo busca dar cuenta de la relación que existe entre la escasa aplicación de la figura del daño social y la política criminal costarricense, a través de sus caracterizaciones, partiendo de la concepción teórica real objetiva donde se comprenden como dos fenómenos complejos. De ahí que se buscó dar respuesta a la pregunta ¿qué lugar ocupa el daño social en la política criminal del país? Lo anterior en el marco de la teoría de daños, $y$ de las posibles afectaciones a la colectividad $y$ al bienestar social.

PALABRAS CLAVE: POLÍTICA * CRIMEN * DAÑO SOCIAL * ADMINISTRACIÓN DE JUSTICIA * BIENESTAR SOCIAL

\section{ABSTRACT}

This article seeks to account for the relationship that exists between the scarce application of the figure of social damage and the Costa Rican criminal policy. It is through their characterizations, starting from the real objective conception where they are understood as two complex phenomena. Hence, an attempt was made to answer the question: what place does social harm have in the country's criminal policy? This is in the context of the theory of damages, and of possible effects on the collectivity and social welfare.

KEYWORDS: POLITICS * CRIMINALITY * SOCIAL HARM * ADMINISTRATION OF JUSTICE * SOCIAL WELFARE 


\section{INTRODUCCIÓN: NUESTRO PUNTO DE PARTIDA}

Uno de los retos principales del análisis de los aspectos jurídicos desde la ciencia social, es el tener claro las múltiples dimensiones que componen este objeto de estudio, precisamente, este es uno de los aspectos a considerar cuando se busca estudiar la relación entre política criminal y daño social, así como los impactos que este vínculo puede significar.

Sin duda son dos temáticas de gran actualidad, tanto en el ámbito nacional e internacional, ya que se reconoce que un hecho punible $y$ no punible puede afectar los intereses $y$ derechos $^{1}$ de la colectividad.

Cuando se plantea el tema de la política criminal $^{2}$, se debe partir de una concepción amplia, en donde se comprenda como toda acción u omisión de los poderes públicos del Estado tendientes a reprimir o prevenir el delito. Siendo parte de la política general de la colectividad, del gobierno, donde se torna preciso integrarla en la política social enlazada con "los grandes objetivos de la democracia, de la igualdad, seguridad y solidaridad" (López-Rey, 1978, p. 343).

Por ello, dicha política criminal encuentra su justificación en la expresión de un poder político democráticamente constituido, objeto de la criminalidad convencional y no convencional, reduciéndo al mínimo necesario el catálogo de las conductas sancionables y garantizando una participación amplia de la comunidad. La política criminal tiene un papel destacado en la utilización de la violencia, que al menos se pretende legítima (Rivera, 2015b).

La discusión sobre la política criminal resurge al finalizar la Segunda Guerra Mundial, como una reacción contra el autoritarismo penal. Ello, con el fin de renovar $y$ fortalecer un derecho penal garantizador, en lo que respecta al límite del poder estatal y de las garantías del debido proceso (Navarro, 1992). Siendo, una facultad delegada por la sociedad, que busca que

1 Para ampliar el tema revisar Aguirre y Sibaja, 2010.

2 Ver Rivera (2005b), quien hace un análisis epistemológico e histórico del concepto de política criminal. el Estado dirija y organice una respuesta al fenómeno de la criminalidad dentro de un marco democrático de legalidad. Al respecto, Acevedo (2004) señala que la política criminal:

... no sólo se circunscribe a las conductas que se evaluaron como delitos y a las cuales se le asignaron una sanción; implica además, una serie de repuestas extrapenales que se realizan muchas veces con participación de organismos no gubernamentales o grupos sociales, tendientes a la prevención temprana de la criminalidad $y$ en la mayor o menor frecuencia de ciertas formas delictivas. Así, el objeto de estudio de la política criminal se encuentra integrado no sólo por el derecho penal sino también por aquellas instituciones que tengan como fin, desde la perspectiva política, la prevención y el control del delito y la criminalidad (p. 41).

Por tanto, la política criminal supone el análisis de todo el sistema de control social y de las medidas preventivas que están dadas por las políticas públicas desde los más diversos ámbitos de la estructura social; lo que implica una comprensión interdisciplinaria de los distintos aspectos que conforman el proceso de criminalización social. Espinoza (2007) indica que:

... el control social es una expresión concreta de la política general del Estado y uno de los aspectos de esta política es precisamente la Política Criminal. Esta política plantea los criterios básicos del sistema de justicia penal, pero no toda reacción estatal dirigida a evitar comportamientos delictivos o suprimir ciertas situaciones criminógenas forman parte de la Política Criminal; aunque ésta goza de una cierta autonomía en el marco de la política estatal, se integra, más bien, en una perspectiva vasta de política social, ya que una buena política social constituye una condición indispensable para organizar y desarrollar una Política Criminal eficaz. Sin embargo, no todo el ámbito social abarcado por 
la Política Criminal constituye un dato objetivo, pues las nociones de delincuencia, crimen o criminal, son el resultado de discusiones sobre criterios de Política Criminal; criterios que condicionan la determinación de los comportamientos que deben ser criminalizados (p. 102).

En esa línea se enmarca la definición de Max Weber (1979) del Estado, al indicar que "por Estado se debe entender un instituto político de actividad continuada, cuando $y$ en la medida en que su cuadro administrativo mantenga con éxito la pretensión al monopolio legítimo de la coacción física para el mantenimiento del orden vigente" (p. 92).

Teniendo, no solo repercusiones al interno de los Estados, sino también en el ámbito internacional, donde se cuenta con instituciones $y$ organizaciones que a dicho nivel se ocupan de la criminalidad, de los criminales o de sus víctimas, $y$ que se traducen en una diversidad de acciones colectivas. Navarro (1992) indica que:

... ni la definición del concepto, ni los alcances del mismo, ni las perspectivas hacia lo que puede o debe tener la política criminal son pacíficas. Desde diferentes perspectivas, la discusión de la política criminal siempre reconduce en alguna manera al tema de reforma del derecho vigente (p. 73).

Asimismo, la autora señala que "la política criminal es un fenómeno complejo, que se desencadena en una decisión, la cual va configurando un proceso dinámico, permeable e inmerso en las contradicciones, tácticas y estratégicas del poder" (Navarro, 1992, p. 4). Por otro lado, algunos autores señalan:

Así mismo, tiene un componente de manejo de la violencia legítima, cuando se encarcela, cuando se arresta o la policía enfrenta a una banda armada; sin embargo, lo cierto es que como política pública tiene condicionantes en los elementos de la política democrática: legitimación ciudadana, división de poderes, control ciudadano, transparencia y deliberación, si se olvidan será política criminal, pero no será democrática (Urcuyo, 2010, p. 133).

Entonces al ser la prevención de la delincuencia, el objetivo fundamental del sistema $y$ del control social en general, viene a constituir el eje de toda Política Criminal moderna, afirma Zúñiga (2001, p. 39), ya que la cuestión de la racionalidad de la prevención estará centrada en sus límites, en el respeto a los parámetros de licitud $y$ en la actuación de los poderes públicos y privados (Espinoza, 2007, p. 105).

Por ello, es que la política criminal y el derecho encuentran cabida dentro de ese marco, además de un destacado rol en el uso legítimo de la fuerza y en su configuración dentro de la estructura social.

Junto con ello, la figura del daño social se encuentra regulado en Costa Rica y forma parte del artículo 50 de la Constitución Política, según el cual todos tienen derecho a vivir en un ambiente sano y en bienestar social. Refiriéndose a la percepción de bienestar que produce la protección de los intereses difusos y colectivos, tanto materiales como inmateriales, así como, la percepción de seguridad o inseguridad que se tenga en un espacio social.

Esta figura se introduce en el Código Procesal Penal de 1996 como un concepto de daño novedoso y poco regulado en nuestro ámbito jurídico. Específicamente, el artículo 38 de dicho cuerpo normativo establece la posibilidad de que la Procuraduría General de la República indague el resarcimiento, mediante una acción civil, de aquellas afectaciones ocasionadas a los intereses difusos y colectivos por un hecho punible.

El daño social a pesar de ser parte de nuestro ordenamiento, ha tenido muy poco desarrollo doctrinario y escaso análisis jurisprudencial (Procuraduría de la Ética, 2017; Llobet, 2006). Sin embargo, en los últimos años, la Procuraduría ha decidido utilizarla al intentar cobrar este daño en procesos relacionados con las afectaciones al ambiente, por asuntos tributarios 
$y$ recientemente, por temas relacionados con la corrupción en la función pública ${ }^{3}$.

Lo anterior, ha posibilitado que la figura del daño social sea parte del debate nacional $y$ de la discusión jurídica ${ }^{4}$. Siendo también un tema, que a nivel internacional ha tomado importancia, donde se conoce también como "social harm" (Rivera, 2005b) y ha logrado redefinir el objeto de análisis de la criminología.

El daño social es un instrumento de poder social, con el que se evidencia que cuando el delito produce daño colectivo, afecta la totalidad de la estructura social, no solo a la víctima, sino al resto de los individuos que configuran la realidad colectiva.

Lo anterior, considerando al derecho como una ciencia social y por tanto, una construcción colectiva que para ser explicada debe referirse a una realidad específica, ubicada en un tiempo y espacio determinado.

Por ello, se plantea la relevancia de conocer y analizar las dimensiones sociopolíticas que caracterizan la figura del daño social en Costa Rica, dentro de la actual política criminal del país.

\section{LA POLÍTICA CRIMINAL COSTARRICENSE}

A pesar de lo señalado en el apartado anterior sobre la política criminal, en el país la discusión indicada no es tan clara y no se dá una amplia comprensión del tema desde la perspectiva integral. Existe una tendencia a pensar la política criminal solo desde la reforma del derecho penal vigente (más delitos y más penas), sin considerar los demás elementos que la componen.

Tal y como se indicó, la política criminal se configura como una reacción estatal ante aquellos comportamientos que se consideran dañinos en una sociedad, manifestándose por medio de los órganos de control social formal. Siendo la suma, por un lado, de la política social y, por otro lado, de la política penal, la

3 Ver la jusrisprudencia relacionada con el daño social en la página de la Procuraduría de la Ética, 2017.

4 Debido a las causas "cCSs-Fischel" e "ICE-Alcatel", el daño social se ha convertido en una figura de interés en el ámbito nacional. primera se relaciona con la prevención primaria, mientras que la segunda se caracteriza por abocarse a la corrección de aquellos incumplimientos de la norma.

Sin embargo, el primer rasgo característico de Costa Rica es que se tiende a comprender la política criminal, como sinónimo de política penal, lo que se hace evidente cuando se pretende eliminar la delincuencia y reducir la inseguridad social, desde la tipificación desmedida de aquellos comportamientos que se consideran dañinos para el ordenamiento jurídico. A partir de lo anterior, el legislador constituye lo que se conoce como criminalización primaria, estableciendo políticamente que se entiende por delito $y$ fijando cuales son las conductas prohibidas, siendo la fase en la que se define la juridicidad de los hechos, $y$ con ello quienes son los delincuentes y quiénes no. Al respecto, Sánchez (2011) afirma que en el país después del año 1994:

... suceden una serie de modificaciones dirigidas al endurecimiento de la sanción para algunos delitos, el aumento del límite máximo de la pena de prisión a los cincuenta años y la supresión parcial del descuento por trabajo carcelario. Tales reformas fueron anunciadas en su momento como fórmulas imbatibles para luchar contra la criminalidad, siendo que al día de hoy no han logrado su objetivo declarado, sino que han permitido que el hacinamiento de las prisiones alcance cifras inéditas, un significativo aumento en la violencia intramuros, crecimiento continuo de la tasa de encierro, $y$ en general, un vergonzoso escenario de violación de derechos humanos de la población encarcelada. Además, los cambios implementados suponen una contradicción con los fines de reinserción social que supone la sanción penal (p. 433).

A ello se suma el uso político del derecho penal, que satisface las supuestas demandas sociales de endurecimiento efectivo de la ley para una mayor seguridad, se presenta como un peligroso instrumento de comunicación que permite trasladar los problemas y conflictos sociales a un tipo de análisis específico. 
Además, la criminalidad tiene valor comercial para los medios de comunicación que lo utilizan como una mercancía de la industria cultural. Se asiste entonces a una lamentable teatralización de la persecución penal, aprovechada por los partidos políticos — con fines electoralistas - y masificada por la prensa para vender más periódicos, con un único resultado: la relativización de los derechos fundamentales y las garantías constitucionales de los individuos, y una sociedad cada vez más reprimida y adicta al sistema penal (Traverssa, 2014).

Lo señalado da cuenta de una política criminal en el país que tiene como propósito la persecución penal, sin considerar otros aspectos. Por ello, se pueden señalar como sus principales características las siguientes:

$\diamond \quad$ Predominio de la perspectiva clásicoindividualista del derecho penal. Esto significa que la política criminal del país fija su mirada en aquellos delitos contra intereses individuales, como la vida e integridad, propiedad y la libertad, ligados con la delincuencia clásica. Con esto se plantea que la víctima es un individuo determinado, y el centro del desarrollo jurídico es el delincuente, como causante de la conducta dañina.

El problema de la inseguridad ciudadana. El tema de la delincuencia clásica encuentra su sustento en la creciente percepción de inseguridad de la población; siendo este tema central en tanto existe una preocupación generalizada sobre la delincuencia y sus diversas manifestaciones; así como, una constante preocupación por ser víctimas de un delito. Al respecto, Mesén (2012) plantea que el tema de la seguridad social es una:

... problemática social, unilateralmente visualizada por el ciudadano común desde el ámbito de la criminalidad y de lo penal, dirige a importantes sectores de nuestra población hacia la conformación de respuestas autoritarias, crecientemente represivas. El ciudadano no percibe la complejidad del fenómeno, limitándose a una impresión parcial y deformada, contraria a la defensa de sus escasos derechos, y obsesionada con la confusión de su equiparación con la seguridad de la punición (p. 140).

Asimismo, Sánchez y Murillo (2010) plantean que:

la influencia de los medios de comunicación, ha contribuido en gran manera a desarrollar en la población costarricense la idea de un incremento desmedido de la delincuencia, y por ende un sentimiento de inseguridad que no se corresponde con la realidad. Esta sensación de inseguridad se da sobre todo, respecto de delitos que involucran grave violencia, delitos sexuales, delitos patrimoniales y los relacionados con el tráfico de drogas y estupefacientes. Ese manejo mediático de los hechos relacionados con la criminalidad, ha provocado que dentro de la Asamblea Legislativa de Costa Rica, se recurra a la discusión y aprobación de leyes dirigidas al aumento de las penas, así como a la creación de nuevos tipos penales que pretenden acudir a la salvación de la sociedad. Sin embargo, en contradicción con el imaginario social, la falta de definición de adecuadas políticas criminales, la sobre-utilización del sistema penal como respuestas a los problemas sociales, el aumento de penas privativas de libertad y medidas cautelares, provocan un efecto negativo en la sociedad que lejos de aliviar el sentimiento de seguridad ciudadana, amenazan con la flexibilización de los derechos fundamentales y renuncia a las garantías procesales, en busca de un Estado que pueda obtener un control de las actividades de sus ciudadanos (pp. 110-111).

$\diamond \quad$ Uso desmedido del instrumental punitivo, más delitos y aumento de las penas. Por lo antes mencionado, se ha configurado una 
política criminal cada vez más represiva, por medio del derecho penal, en tanto se considera que éste es el ente más "eficiente" en garantizar seguridad ciudadana. Al respecto, Alfredo Chirino aseveró "que no existe una política nacional sobre el tema de la criminalidad, sino que lo único que se ha agregado son reformas legales que consisten en más delitos y mayores penas" (Chacón, 2011, p. 10). Es una política criminal caracterizada por la creación de nuevos delitos o bien por agravar las penas de los ya existentes, "se concentra en los tipos penales $y$ en las combinaciones sin interesarle las consecuencias que ello pueda generar. $\mathrm{Al}$ mismo tiempo, que se extiende su ámbito de actuación a aquellos sectores que en la opinión pública se consideran más amenazantes contribuyendo con ello, a estigmatizar a ciertos grupos sociales" (Acevedo, 2004, p. 43).

Siendo que el Código Penal ha sufrido un total de 296 reformas, producto de 61 leyes de las cuales son de especial importancia las número 7389 y 7398 del año 1994. Según Sanchéz (2011):

... ambas se constituyen en el verdadero parteaguas de la oficialización legislativa de la nueva "lucha" contra la delincuencia: la primera aumenta el tope máximo de las penas de 25 a 50 años, y la segunda elimina la posibilidad de descuento por trabajo en la primera mitad de la condena (p. 447).

Realidad que en lugar de dar una solución al tema lo agrava, al deshumanizar al delincuente, dejando atrás un sistema penal garantista $y$ acercándose cada vez más al punitivismo penal, lo que se evidencia en el análisis del sistema penitenciario del país, donde el hacinamiento, el reducido presupuesto, la falta de infraestructura y la deficiente calidad de la vida de los prisioneros no son más que sus consecuencias.
Por tanto, se da un fuerte expansionismo del derecho penal sobre la base de la excesiva criminalización y penalización; todo en procura de garantizar la seguridad ciudadana.

$\diamond \quad$ Por último, la política criminal como un tema electoral. Como consecuencia de lo anterior, los temas relacionados con la seguridad ciudadana y la justicia, han permitido a los políticos capitalizar un buen número de votos al plantear dentro de sus agendas estos problemas; donde la politización de la justicia penal, es utilizada para responder a la opinión pública y las demandas sociales, como el único mecanismo al fenómeno de la criminalidad; dejando con ello de lado, el análisis de las verdaderas causas sociales y económicas que están en el fondo y que se invisibilizan.

De este modo, la "política criminal" del país son conducidas por las encuestas de opinión, con el objeto de mejorar la credibilidad ya deteriorada que tiene la población con respecto a la justicia, ante la creciente desconfianza que ha generado el funcionamiento policial y el sistema jurídico en general para la solución de los conflictos sociales (Acevedo, 2004, p. 45).

Con ello, es evidente el poco interés en crear una política criminal integral y conciliadora de todas las dimensiones que componen la estructura social, en busca de un mejor entendimiento y de una solución al tema de la criminalidad.

\section{EL DAÑO SOCIAL Y LA POLÍTICA CRIMINAL}

A partir de lo anterior, cabe preguntarse ¿qué papel ocupa la figura del daño social dentro de la política criminal del país? Y ¿por qué a pesar de haberse configurado como parte del ordenamiento jurídico nacional, no se ha aplicado ampliamente? 
Para dar respuesta a estas dos preguntas, se debe partir indicando que los cambios actuales en la sociedad son producto del proceso globalizador, incluyéndose con ello la importancia de las colectividades $y$ de los posibles daños que estas puedan sufrir; siendo insuficiente su abordaje desde el derecho tradicional individual (Rivera, 2015b).

Dicho contexto ha propiciado un cambio en las relaciones entre el individuo y la sociedad, implicando dejar atrás los dogmas clásicos del derecho y por otra parte, aceptar la necesidad de tutela para las personas vinculadas con una necesidad común (Aguirre y Sibaja, 2011). El daño social es:

... una figura que presenta un rango de aplicación muy vasto en razón de su naturaleza colectiva. Este nacerá y será siempre reclamable cuando se vulneren intereses difusos o colectivos, no siendo relevante el tipo de acción con la cual se ocasione; pero sí es tutelable su reparación en alguna de las vías ya mencionadas, según las características del interés vulnerado, $y$ en tanto se cumplan los requisitos para la configuración del mismo daño (Aguirre y Sibaja, 2011, p. 154).

Ante ello, no resulta extraño que el sistema jurídico del país, en lo relativo al daño social, haya tenido escaso desarrollo, careciendo de amplio análisis doctrinario y de muy poco abordaje jurisprudencial. Lo anterior es repuesta del desarrollo histórico sobre el tema criminal en Costa Rica, tal y como lo plantea Huhn (2012) cuando señala que:

... primero había una clara preocupación pública sobre la criminalidad como problema social durante toda la segunda mitad del siglo xx $y$ éste se parece mucho en sus facetas centrales al discurso actual. Y segundo, este tema se transformó en los años 90 cuando los presidentes expresaron su optimismo acerca de sus políticas contra el crimen y refirieron sus políticas de mano dura contra los criminales. Tercero, finalmente se mostró que la tematización pública y la problematización fueron vinculados con procesos políticos regionales y globales (p. 84).

No fue hasta que la Procuraduría General de la República, hace ocho años atrás, inicia con el cobro por daño social en los procesos que consideraba de relevancia colectiva. Sin embargo, a pesar de su esfuerzo, el abordaje de la figura no fue amplio y no permitió, ni permite un claro conocimiento de esta.

Lo que tiene sentido, cuando se analiza la configuración de la política criminal en el país, ya que tal y como se indicó, está pensada solo desde el derecho penal clásico individualista, en el cual los reclamos colectivos no encuentran espacio, $y$ a pesar de que lo podrían tener, no se reconoce ni se le da la importancia que merece. Más bien, por las características señaladas de la política criminal, esta se ha configurado desde una perspectiva contraria a la protección de los derechos colectivos, invisivilizándolos dentro de la cuestión de la criminalidad individual, al exponer unicamente el tema vinculado con la seguridad social.

Con ello, la política criminal ha fijado su mirada sobre los delitos o ilícitos que afectan los intereses individuales, ligados a una forma tradicional de pensar la criminalidad, donde la víctima es un sujeto determinado. Al tener como eje de análisis central la relación delincuente-víctima, tutelando primordialmente aquellos bienes jurídicos ligados a esos intereses particulares, no se contemplan las posibles afectaciones a los intereses difusos y colectivos, como la que se da con la corrupción política o bien, cuando se vulneran derechos vinculados con la diversidad sexual o género, $y$ hasta los derechos de las mismas personas privadas de libertad, entre muchos otros.

A pesar de que el daño social se encuentra regulado en el Código Procesal Penal, en el artículo 38 de la ley, por un lado, parece un inclusión innovadora y acorde con la realidad social actual, pero cuando se analiza la práctica y utilización de la figura, ante la ausencia de justificación en las actas legislativas de misma, se hace evidente que se ubica en la norma, pero no se conocen sus alcances e implicaciones. 
Por ello, es necesario para realizar el análisis del daño social, recurrir al fundamento legal contenido en los artículos 41 y 50 de la Constitución Política, además de normas especiales como el Código Civil.

La Constitución Política establece en el numeral 41, la garantía general y el derecho de resarcimiento al indicar que "ocurriendo a las leyes, todos han de encontrar reparación para las injurias o daños que hayan recibido en su persona, propiedad o intereses morales", lo cual conlleva el deber de reparar, de aquel sujeto o sujetos que con sus acciones, omisiones o mediante la creación de un riesgo, cause un daño a otro. Asimismo, este deber se encuentra fijado en el artículo 1045 del Código Civil, según el cual "todo aquel que por dolo, falta, negligencia o imprudencia causa un daño a otro, está obligado a repararlo junto con sus perjuicios".

Estas normas demuestran la importancia del daño y su efectiva reparación. Son pilares para el surgimiento de la responsabilidad civil y por tanto de su regulación en el derecho penal, permitiendo la reparación de los daños causados a personas en su carácter individual o bien, a las colectividades.

Por tanto, se parte de una concepción amplia de daños, donde las distintas conductas humanas son comprendidas $y$ sus posibles afectaciones deben ser reparadas.

Ante ello, cabe reconocerse que el daño a intereses jurídicamente relevantes pueden darse también como resultado de hechos ilícitos en materia penal; con lo cual surge el tema de la responsabilidad civil, la obligación de reparar los daños causados, producto de la afectación a intereses y derechos ajenos. La vía de lo extracontractual es el mecanismo pertinente para la reparación de los daños sociales, ya que no es producto de una vinculación previa entre las partes, sino se da del deber genérico de reparar (Rivera, 2005b).

Todo ello permite extender la tutela legal ante resultados que pueden resultar dañinos a la colectividad; lo que responde de cierta forma, a los cambios sociales, nuevas circunstancias $y$ exigencias de los individuos. Los intereses difusos y colectivos son principios fundamentales de todo cuerpo normativo, aspectos jurídicos que se han desarrollado en diversos países; particularmente por el tema mencionado de la expansión del derecho en el aspecto de los daños, en tanto resultan de relevancia para el desarrollo de la vida colectiva y del bienestar social.

El daño social presenta una amplia diversidad de aspectos, que van desde su definición, hasta cuestiones instrumentales y procesales, cuyos límites no son tan precisos (Rivera, 2005b). Es claro que debería tener un espacio y ser parte de la configuración de la política criminal en Costa Rica, situación que hasta el momento no ha acontecido de manera plena $y$ cuyos incipientes intentos no han dado el resultado esperado en la legitimación, el reconocimiento en el ámbito jurídico y social de la importancia de la tutela de este tipo de daño. Esto deja en evidencia la necesidad de una mayor utilización en la práctica, como parte de los reclamos ante los tribunales de justicia.

De ahí que, se requiere un planteamiento distinto de la política criminal del país, en tanto garantice su comprensión integral que vaya más allá del derecho penal y que logre incorporar la realidad social como un eje transversal que guíe su definición; lo que supone establecer los parámetros "político-criminales en un sistema dado, así como por la construcción, en el amplio campo de las relaciones sociales y políticas, de las nuevas líneas de la política criminal" (Navarro, 1992, p. 76).

Así mismo, es relevante tener claro que el daño social no se reduce únicamente al campo del derecho penal, como podría pensarse. Si bien, la legislación lo que prevé es su reclamo, cuando es consecuencia de la comisión de un delito, la figura en sí, tiene un destino práctico más cercano al derecho civil; pues se busca su resguardo por medio de una acción civil resarcitoria (Aguirre y Sibaja, 2011).

La figura necesita de una aplicación mayor para poder definir parámetros y ejes de interpretación. En razón de esto, es pertinente tener claro que es una figura en desarrollo jurídico, donde la adecuada identificación del daño, su cuantificación, la legitimación activa y la necesidad de nuevos mecanismos judiciales para presentar su reclamo, son aspectos que deben ser considerados. 
Es claro de que falta mucho camino por recorrer en el ámbito legislativo y jurisdiccional con el fin de garantizar la adecuada aplicación del daño social, pero sobre todo se requiere de una mayor voluntad política que propicie el reconocimiento y la importancia de las afectaciones a la colectividad, además de que las conductas delictivas con independencia de su tipo, pueden tener implicaciones de esta naturaleza.

El reto está en configurar una política criminal comprensiva de la realidad colectiva, ya que por medio de esta se garantiza mejor el bienestar del país.

\section{CONSIDERACIONES FINALES}

Se plantea en última instancia, que el daño social como figura jurídica, es un indicador sociocultural, el cual en su construcción reúne un conjunto de representaciones sociales que determinaron su creación. Por lo que en ciertos hechos delictivos, pueden producir afectaciones a otro ser humano o a la sociedad, lesionando intereses particulares, sean individuales o colectivos. Puede decirse que el acto delictivo engendra responsabilidad civil.

De ahí que la juridicidad del hecho responde a ese espacio social. En este sentido, los delitos como hechos jurídicos son una construcción social, es una definición jurídica que surge de grupos específicos orientados a proteger sus intereses, todo dentro de la realidad capitalista que determina a las personas, donde se destacan sus causas sociales y culturales ubicadas en un tiempo y espacio dado.

Sin dejar de lado la caracterización de la sociedad actual, donde los conflictos se convierten en asuntos colectivos; ya no solo es posible hablar de daños que afectan el carácter individual de las personas, sino que se deben comprender aquellos que afectan a la sociedad, como la contaminación ambiental, los temas relacionados con el consumidor o bien, la corrupción pública de sus funcionarios ${ }^{5}$.

$5 \quad$ Para profundizar sobre las aplicaciones concretas del daño social ver Aguirre y Sibaja, 2011.
La responsabilidad por daños es una temática muy compleja y amplia, que se vincula con muchos aspectos de la vida social.

El derecho de daños es el que legitima la temática de los intereses difusos (a un grupo de personas no identificables) y colectivos (grupo de personas determinados), pero sobre todo el desarrollo actual que tiene el término del daño social. Aunado al reto de convertir esta nueva realidad, en hechos jurídicos y por ende, tutelados en el ordenamiento por medio de la política criminal.

Comprender el daño social, supone desde esta perspectiva efectuar un adecuado análisis de las dimensiones sociales y políticas que le dieron origen y que lo determinan. Esto es posible a través del estudio de los textos legislativos que fundamentan la creación de la figura, $y$ que permiten conocer su ubicación dentro del contexto jurídico costarricense y el papel que juega en la política criminal del país.

Lo anterior recuerda que el discurso jurídico es una construcción social, el cual se reproduce a la largo de la vida, en distintos niveles, dependiendo de la posición que se ocupe determinado por el tiempo y el espacio. Por ello, el daño social como figura, no es más que una respuesta jurídica de las condiciones sociales y culturales que le dieron origen.

Asimismo, resulta interesante analizar que en el ámbito internacional la forma en que se comprende el daño social supone una regulación mucho más amplia, ubicando este tema en el actual contexto de violencia estructural, en el cual los hechos delictivos responden a un contexto social nacional e internacional que los propicia; donde se comprenda la política criminal como toda acción u omisión de los poderes públicos del Estado tendientes a reprimir o prevenir el delito. Por ello, dicha política criminal encuentra su justificación en la expresión de un poder político democráticamente constituido, objeto de la criminalidad convencional y no convencional, donde debe reducirse al mínimo necesario, el catálogo de las conductas sancionables y se busca garantizar la participación amplia de la comunidad.

Sin embargo, en el país no existe una comprensión del tema desde la perspectiva integral, ya que se piensa en política criminal solo 
desde la reforma del derecho penal vigente. Ni en el ámbito doctrinario ni jurisprudencial se cuenta con claridad sobre las dimensiones y alcances del daño social en Costa Rica; si bien se encuentra regulada expresamente la figura en el Código Procesal Penal, no ha tenido un amplio desarrollo. Asimismo, por las características de la política criminal, no tiene un rol protagónico.

De ahí que uno de los elementos que priva en la configuración de la política criminal es la perspectiva clásica individualista del derecho, donde el delincuente es el centro del desarrollo jurídico, posición que obstaculiza el análisis de las posibles afectaciones a los intereses difusos y colectivos, que algunas conductas delictivas pueden producir.

Además, se tiene un ámbito de acción mínimo con motivo de la regulación planteada en el artículo 38 del Código Procesal Penal, ya que refiere directamente a la afectación producida a la colectividad con ocasión de un hecho punible, como por ejemplo, delitos ambientales, delitos tributarios, malversación de fondos públicos, delitos de corrupción y con ocasión de la función pública.

Por ello, existe la necesidad de una comprensión amplia de este, que incorpore hechos que no siempre son punibles, pero que pueden afectar a un grupo social, tal es el caso de daños ocasionados al medio ambiente, a la salud, vicios de los productos de consumo, falta de acceso a servicios públicos, entre otros. Todos igualmente englobados dentro del concepto de ambiente sano que tutela la Constitución Política, siendo posible su tutela en otras vías procesales como la civil, la contencioso administrativa o bien, la constitucional, en las cuales a través de los diferentes mecanismos establecidos es posible solicitar el cobro o reparación del daño social, garantizando su carácter crítico y ampliando la tradicional concepción de la teoría de daños.

Se trata de comprender las dinámicas históricas sociales e individuales (los discursos) que están detrás de este fenómeno colectivo, como lo es la política criminal y el daño social dentro de esta, siendo aún un reto pendiente.

\section{REFERENCIAS}

Acevedo, M. (2004). La política criminal contemporáneay la práctica penitenciaria costarricense. Revista de Ciencias Jurídicas de la Universidad de Costa Rica (3), 39-51.

Aguirre A. L. y Sibaja, I. (2011). El daño social: su conceptualización y posibles aplicaciones. Revista Judicial, (101), 129-160.

Baratta, A. (2004). Criminología crítica y crítica del derecho penal. Buenos Aires, Argentina: Siglo xxı.

Código Civil. (2016). San José, Costa Rica: Editorial Investigaciones Jurídicas, s.A.

Código Penal de Costa Rica. (2016). San José, Costa Rica: Editorial Investigaciones Jurídicas s.A.

Código Procesal Penal. (2016). San José, Costa Rica: Editorial Investigaciones Jurídicas s.A.

Constitución Política de Costa Rica. (2016). San José, Costa Rica, Editorial Editec Editores, s.A.

Creus, C. (1995). Reparación del daño producido por el delito. Buenos Aires, Argentina, Editorial Rubinzal-Culzoni.

Espinoza, B. (2007). Política Criminal y Prevención del Delito Hoy. Una Propuesta de Modelo de Prevención para el Municipio de León, basado en la Participación Ciudadana. (Tesis para optar por el grado de Doctorado en Derecho), Universidad Estatal a Distancia.

Huhn, S. (2012). Criminalidad y discurso en Costa Rica: reflexiones críticas sobre un problema social. San José, Costa Rica: Editorial FLACso.

Llobet, J. (2006). Proceso Penal Comentado (Código Procesal Penal Comentado). San José, Costa Rica: Editorial Jurídica Continental.

López-Rey, M. (1978). Criminología: Criminalidad y planificación de la política criminal. España: Aguilar Ediciones, Tomo II.

Mesén, A. (2012). Prevención general positiva y derecho penal simbólico en la política criminal costarricense. (Tesis para optar por el grado de Licenciatura en Derecho), Universidad de Costa Rica, Costa Rica. 
Navarro, S. (1992). Fundamentos doctrinarios en la configuración de la política criminal. En Consideraciones en torno a una nueva politica criminal en Centro América y Panamá. Costa Rica: ILANud.

Procuraduría de la Ética. (2017). El daño social. Recuperado de http://www.pgr.go.cr/ pep/temas-de-interes-pep/dano-social/

Rivera, I. (2005). Recorridos y posibles formas de penalidad. Barcelona, España: оspDH, Universidad de Barcelona, Anthropos Editorial.

Rivera, I. (2005b). Política criminal y sistema penal: viejas y nuevas racionalidades. Barcelona, España: ospdi, Universidad de Barcelona, Anthropos Editorial.

Sanchez, C. y Murillo, R. (2010). Inseguridad, miedo, enemigos y víctimas. En Duran, D y Llobet, J. (2010) Política criminal en el estado social del derecho. San José, Costa Rica: Editorial Jurídica Continental.
Sanchéz, H. (2011). Las reformas al Código Penal y sus consecuencias en las prisiones: el caso Costa Rica. Revista Digital Revista Digital de la Maestría en Ciencias Penales de la Universidad de Costa Rica (3), 443- 455.

Traverssa, R. (2014). Neopunitivismo y control social. Reflexiones sobre la represión selectiva de la política populista. Revista Panorama. 15 (8), 133-143.

Urcuyo, C. (2010). La obsesión con la seguridad y la reforma procesal penal. En Duran, D. y Llobet, J. (2010) Política criminal en el estado social del derecho. San José, Costa Rica: Editorial Jurídica Continental.

Weber, M. (1979). El político y el científico. Madrid: Alianza.

Fecha de ingreso: 10/10/2017 Fecha de aprobación: 19/06/2018 
